\title{
Emoções e ações de professores ao falar inglês no WhatsApp
}

\section{Teachers' emotions and actions when talking in English on WhatsApp}

Rodrigo Camargo Aragão*

Universidade Estadual de Santa Cruz - UESC

Ilhéus, Bahia / Brasil

RESUMO: Este trabalho tem como objetivo compreender o papel das emoções na experiência de professores em exercício sobre suas interações orais em inglês. A pesquisa foi realizada durante um curso de formação continuada com foco em mobilidade digital, mediado por aplicativo de tecnologia móvel, o WhatsApp. As perguntas norteadoras foram: Como os professores se sentem ao usar o recurso de áudio para falar inglês no WhatsApp? $\mathrm{O}$ fato de as mensagens de áudio serem feitas via WhatsApp deixou-os mais à vontade do que em um encontro presencial? A metodologia é de base qualitativa com uso de questionário, entrevista e representações visuais das emoções. Os resultados indicam que parte dos participantes se sentiram mais confiantes e mais dispostos a se comunicar no WhatsApp do que em contextos face a face. Por outro lado, outro grupo se sentiu mais inseguro para falar inglês com os recursos de gravação de áudio. Os resultados serão discutidos à luz da literatura revisada, assim como das potencialidades dessa tecnologia móvel para o desenvolvimento de habilidades orais na formação de professores de inglês.

PALAVRAS-CHAVE: habilidades orais; inglês; aprendizagem móvel; tecnologias assíncronas.

ABSTRACT: This paper aims at researching the role of emotions in the experience of oral skills interactions in an in-service teacher education course with a focus on mobile learning mediated by WhatsApp. The research questions were: How do teachers feel when speaking in English through the audio recorder device of WhatsApp? Did they feel more at ease with the audio message system of WhatsApp in comparison to face-to-face interaction? This is a qualitative study and data were collected by means of a questionnaire, a semi-structured interview, and visual representations of emotions. Results suggest that part of the participants felt more self-confident and more willing to communicate at WhatsApp when compared to face-to-face contexts. On the other hand, another group of participants felt more insecure to speak in English with the

* aragaorc@gmail.com 
audio recorder of WhatsApp. Research results will be interpreted in light of the reviewed literature and potentials and limitations of this mobile technology for oral skills development in language teacher education will also be discussed.

KEYWORDS: oral skills; English; mobile language learning; asynchronous technologies.

\section{Introdução}

Comunicar-nos com outros que estão distantes de nós enquanto nos movemos - ainda que nem sempre em tempo real-é uma das características que marcam a comunicabilidade no mundo contemporâneo. $\mathrm{O}$ rápido desenvolvimento das tecnologias móveis tornou possível que tivéssemos, em um único aparelho, como um smartphone, convergência de imagem, som e texto escrito com conectividade sem fio à internet, gerando informação e comunicação multimodal contínua, em qualquer hora e qualquer lugar. Com um smartphone conectado à internet, expandimos nossa cultura da mobilidade comunicativa já instaurada pelos telefones celulares. O uso de tecnologias móveis de informação e comunicação é parte enraizada do cotidiano de professores e estudantes. As redes atravessam constantemente as paredes e as tecnologias móveis têm impacto no nosso jeito de ser, agir, conhecer e sentir (SIBILIA, 2012). Nesse contexto, conceitos como espaço/tempo, intimidade/privacidade e ausência/presença têm sofrido deslocamentos e ressignificações (COSTA, 2013; PEGRUM, 2014; SANTAELLA, 2014).

No âmbito da aprendizagem de línguas mediada por tecnologias móveis (Mobile Assisted Language Learning - doravante MALL), trabalhos recentes de estado da arte revisam os últimos vinte anos do campo e têm mostrado que o foco principal dos estudos permanece o aprendizado do vocabulário ou da gramática (BOSDOGAN, 2015; BURSTON, 2015). Assim, as habilidades de produção oral não têm sido objeto das pesquisas. Os estudos revisados indicam que tampouco o potencial das tecnologias móveis para interações comunicativas tem sido aproveitado em projetos com estudantes e/ ou professores (BURSTON, 2014; DUMAN; ORHON; GEDIK, 2015). De maneira similar, as habilidades de produção oral não têm sido priorizadas nas pesquisas em ensino/aprendizagem de língua estrangeira (PAIVA, 2007; 2014). Isso contrasta com a importância de se falar uma língua e o impacto desse processo na aprendizagem. No Brasil, assim como em contextos asiáticos, por exemplo, uma das principais dificuldades 
é a falta de práticas comunicativas orais autênticas e significativas (BRASIL, 2006; MCNEIL, 2014; PAIVA, 2006; 2007; TELLES, 2004).

Desde o início da pesquisa em MALL, o foco permanece sendo o envio de conteúdos aos aprendizes, embasado em práticas estruturais de gramática e vocabulário. Burston (2014) argumenta que, embora as habilidades de produção oral não tenham sido pesquisadas, essas são as habilidades que apresentam maior potencial para mobilidade e conectividade entre a comunidade de ensino/aprendizagem de línguas. O futuro do MALL está na adequada exploração dos recursos disponíveis e nas ações potenciais de forma a fundamentar práticas comunicativas, orais e escritas, dentro e fora da sala de aula. Práticas de desempenho oral em inglês podem ser feitas por meio de tecnologias digitais com diversas vantagens para contextos em que o uso da língua fica restrito à sala de aula.

O desenvolvimento de habilidades orais com tecnologias digitais é uma temática recente na área de aprendizagem de línguas mediada por computador (Computer Assisted Language Learning - CALL), área à qual a aprendizagem de línguas mediada por tecnologias móveis está atrelada. No campo da aprendizagem de línguas mediada por computador, pesquisadores têm argumentado a favor do potencial da comunicação que envolve tecnologias digitais como forma de aumentar a motivação de estudantes e de reduzir o medo e a ansiedade de se comunicarem oralmente na línguaalvo em sala de aula (POZA, 2011; MCNEIL, 2014; YANGUAS; FLORES, 2014; SONG, 2009; SUN, 2009).

Como parte de um projeto maior, que tem como um dos seus objetivos avaliar as experiências de estudantes e professores no desenvolvimento de habilidades orais em inglês com tecnologias digitais de comunicação multimídia, ${ }^{1}$ este trabalho enfoca resultados parciais de uma pesquisa sobre o papel das emoções no desenvolvimento de habilidades orais em inglês. ${ }^{2}$ Durante a primeira fase desse projeto, participei do piloto de atividades orais no âmbito da "Taba Móvel”, ação vinculada ao projeto Taba Eletrônica da UFMG. A Taba Eletrônica é um projeto de extensão que toma o formato

\footnotetext{
${ }^{1}$ Trata-se do projeto de Paiva: "Tecnologias digitais para o desenvolvimento de habilidades orais em inglês" (CNPq 303101/2013-0).

2 Projeto: "Complexidade e emoções no desenvolvimento de habilidades orais em inglês" desenvolvido durante residência pós-doutoral no PosLin/UFMG com apoio do CNPq (168419/2014-9).
} 
de uma comunidade tecnológica com experiências ligadas aos letramentos digitais. O projeto oferece ambientes de letramento digital a professores em serviço na educação básica ou a pessoas interessadas nos modos de fazer e pensar com ferramentas digitais. ${ }^{3}$

Em 2015, foi iniciada uma versão móvel do projeto Taba Eletrônica com foco em propostas de ensino/aprendizagem de inglês baseadas na mobilidade digital. Essa experiência de formação continuada tem sido feita através do aplicativo de comunicação multimodal, o WhatsApp. Durante essa primeira fase da formação continuada pelo WhatApp, os professores tiveram a oportunidade de interagir oralmente através do recurso de gravação de áudio do aplicativo integrado às atividades móveis da formação. A literatura revisada indica que aqueles que se sentem mais constrangidos a usarem a língua em contextos face a face podem ser sentir mais confiantes e se arriscarem mais nas interações proporcionadas por tecnologias digitais (POZA, 2011; YANGUAS; FLORES, 2014; SONG, 2009; SUN, 2009). Nessa esteira, pergunto: Como os professores se sentem ao usar o recurso de áudio para falar inglês no WhatsApp? O fato de as mensagens de áudio serem feitas pelo aplicativo deixou-os mais à vontade do que em um encontro presencial?

Em seguida, apresento o referencial teórico que nos fornece subsídios e articula-se à metodologia da seção subsequente. Logo após, apresento a interpretação dos dados e as considerações finais.

\section{0 papel das emoções ao falar inglês com tecnologias digitais}

No contexto brasileiro, pesquisas têm mostrado o desafio que envolve o desenvolvimento das habilidades orais em inglês (ARAGÃO, 2008; BRASIL, 2006; MICCOLI, 2010; PAIVA, 2006; 2007; 2008). Sabemos que uma gama de elementos se inter-relaciona de forma a limitar o desenvolvimento dessa habilidade no contexto das salas de aulas de línguas. As emoções exercem um papel nesse contexto ao limitar frequentemente as ações de expressão oral em inglês (ARAGÃO, 2008; 2011). Os estudantes podem ser bloqueados em seu desenvolvimento por incontáveis emoções: medo de se expor em frente dos outros, de parecer ridículo ao querer expressar um simples pensamento; receio de parecer ignorante; ansiedade

${ }^{3}$ Disponível em: <http://www.tabaeletronica.org/>. 
ao falar em público; medo de ser avaliado negativamente por colegas ou professor; vergonha; inibição; desconforto (MICCOLI, 2010).

Embora as emoções ainda permaneçam pouco pesquisadas na linguística aplicada, há o reconhecimento do que tem sido chamado de "virada afetiva" (PAVLENKO, 2013, p. 19), cujo interesse tem impactado e alargado o espectro da pesquisa sobre o papel das emoções no ensino/ aprendizagem de uma língua (BARCELOS, 2015), um campo conhecido pela sua ênfase nos processos cognitivos (ARAGÃO, 2011; MICCOLI, 2010; NORTON, 2013; PAVLENKO, 2013). O início da pesquisa sobre a temática foi marcado pelo foco na correlação entre variáveis afetivas e resultados de aprendizagem em níveis de proficiência (SCOVEL, 1978). Nessa perspectiva, o objetivo tem sido compreender a variação nos resultados do aprendizado em relação a variáveis afetivas, como a motivação e a ansiedade. Como veremos na próxima seção, a revisão da literatura sobre emoções no desenvolvimento de habilidades orais com tecnologias digitais parece indicar que a ansiedade permanece a variável emocional mais estudada.

Fundamentado em Maturana e Varela (2001) e Maturana (1998) defino aqui as emoções como disposições corporais dinâmicas que embasam os domínios de ações, pensamentos e relações possíveis em determinado momento (ARAGÃO, 2011). Nessa linha, emoções ocorrem na dinâmica corporal e fundamentam ações e relações das pessoas com outras pessoas e dessas com seu meio. Emoção, cognição e ação estão imbricadas. Como são fenômenos biológicos, ${ }^{4}$ as emoções estão relacionadas aos movimentos. É com elas que agimos de maneira expansiva na alegria e na confiança, e no bloqueio ou na restrição na inibição e no medo. Entretanto, na linguagem, ao observarmos nossa própria ação, ou aquela de outra(s) pessoa(s), podemos refletir e dar sentido ao que observamos, e assim falar da emoção como um sentimento (ARAGÃO, 2011). Portanto, os sentimentos são descrições na linguagem das emoções vividas pelos seres vivos.

Seguindo esse quadro teórico ao distinguirmos na linguagem as emoções como sentimentos, fazemos referência à avaliação interpretativa daquilo que observamos como determinada emoção que está presente em

\footnotetext{
${ }^{4}$ Fundamentado em Maturana e Varela (2001), o que distingo aqui como biológico faz referência à dinâmica de um ser vivo em sua experiência sistêmica no viver. Não há ser vivo sem circunstância ecológica e uma rede de relações. Somos o que somos em um meio. No caso de seres humanos, a linguagem, a cognição e a emoção são nossos fenômenos mais íntimos no viver. Como fenômeno biológico, as emoções têm relação com nossas ações.
} 
um momento específico. Parkinson, Fischer e Manstead (2004), por exemplo, nos indicam que os sentimentos implicam uma perspectiva avaliativa diante dos eventos vividos como negativos ou positivos, atribuindo importância, interesse e valor às experiências. Dito em outras palavras, quando nos referimos às emoções vividas como sentimentos, estamos atribuindo sentido a elas como experiências que julgamos positivas ou negativas. Os sentimentos são nossas percepções psíquicas na linguagem daquilo que vivemos como emoções que embasam nossas ações cotidianas. Portanto, os participantes nessa pesquisa indicam seus sentimentos acerca das emoções que impactaram sua experiência ao falar inglês nas atividades do projeto.

Assim, ao seguir esse argumento, a limitação ou a facilidade em se comunicar relaciona-se com determinada disposição para realizar ou não tal ação na linguagem. Há momentos em que certas ações são possíveis ou mais potencializadas que outras, a depender da emoção envolvida. Ao mudar de emoção, mudamos de ação, bem como ao mudarmos de ação tendemos a mudar nossa emoção de maneira interdependente (ARAGÃO, 2011). Seguimos permanentemente nesse fluir, que Maturana (1998) denomina de emocionar. Sob esse enquadre conceitual, emoções relacionam-se com as ações, incluindo aqui o conhecer - atividade de distinguir elementos na linguagem - e o linguajar - a atividade de agir mutuamente e coordenar ações na linguagem. As descrições que fazemos na linguagem de emoções que observamos inter-relacionam-se a crenças e distinções sobre nós mesmos ou sobre como distinguimos nosso ambiente e nossos interlocutores (ARAGÃO, 2011; ARAGÃO; DIAS, 2016).

A expressão de sentimentos negativos sobre o desafio de falar inglês em sala de aula se sobrepõe aos sentimentos positivos, de acordo com pesquisas recentes (ARAGÃO, 2011; MICCOLI, 2010; NORTON, 2013; PAIVA, 2006; 2007). Sentimentos de avaliação julgadora, comparação e competição entre colegas ou professor limitam o desempenho oral em inglês. Esse sentimento ocorre com uma constante preocupação sobre o desempenho oral diante de outras pessoas, um tipo de autoavaliação negativa de seu próprio desempenho que é também influenciado por relações de poder e pela percepção sobre a autoridade dos interlocutores (ARAGÃO, 2011; NORTON, 2013; SULLER, 2004).

Por outro lado, estudos indicam que, com uso de tecnologias digitais de comunicação, há um aumento na disposição para comunicação oral em língua estrangeira (MCNEIL, 2014; POZA, 2011; YANGUAS; 
FLORES, 2014; SUN, 2009). Ainda, notamos que a comunicabilidade tem sido alargada em sites de redes sociais, adquirindo novos contornos e outras formas de agir na linguagem (ARAÚJO; LEFFA, 2016). É possível perceber que, em ambientes digitais, as pessoas costumam se expressar de uma maneira diferente do que elas normalmente fariam se estivessem face a face. É comum observar como as pessoas agem na internet se expondo de uma forma distinta; sem ter que estar frente a frente, as pessoas podem se dispor diferentemente em ambientes digitais. O efeito da desinibição online, fenômeno estudado por Suller (2004), pode ter impactos também na disposição para se comunicar em inglês. $\mathrm{O}$ ambiente digital pode ser favorecido pela ausência de indicadores corporais que marcam posicionamentos de poder, como roupas, linguagem corporal, expressões faciais e postura, além das pistas do ambiente, que podem ser interpretadas como expressões de autoridade pelo interlocutor e tendem a fazer que o outro se sinta inibido e desautorizado a se expressar.

Assim, no contexto digital temos um ambiente que pode potencialmente tornar os interlocutores mais dispostos a se comunicar, sem a constante preocupação sobre a avaliação julgadora ou a interpretação de superioridade ou autoridade de um potencial interlocutor. Outra característica da desinibição online, apontada por Suller (2004), é a minimização de status e a dissociação identitária quando nos percebemos diferentemente no contexto digital, e essa autopercepção nos influencia a agir de uma forma diversa. Aqui, podemos notar como uma distinção diferente de si mesmo e do contexto de uso se associam, - meio e ambiente mudam - e dinâmicas de uso de linguagem também se veem modificadas (ARAGÃO; DIAS, 2016).

As características do recurso para gravação de arquivos de áudio do aplicativo WhatsApp se assemelham a outras tecnologias assíncronas de voz. Por essa semelhança, e por não ter identificado na área de tecnologias digitais móveis pesquisas sobre o desenvolvimento comunicativo de habilidades orais (BURSTON, 2014; 2015), na próxima seção passamos a revisar estudos que trabalharam com a avaliação das experiências de estudantes com tecnologias assíncronas de áudio e suas inter-relações com as emoções dos participantes dos estudos. 


\section{Emoções e comunicação oral com tecnologias digitais assíncronas}

Ferramentas digitais de gravação de voz expandiram as possibilidades de integração de atividades orais no ensino/aprendizagem de línguas, sejam estes contextos híbridos, presenciais ou a distância. Atualmente, temos a possibilidade de gravar nossa voz e transmiti-la por arquivos de áudio por meio de uma variedade de plataformas e redes sociais. ${ }^{5}$ Essas tecnologias, que permitem a interação em locais e tempos diferentes caracterizam-se como tecnologias de vOz assíncronas. Estudos têm indicado que os estudantes avaliam positivamente o uso dessas tecnologias como blogs e fóruns de voz, podcasts e gravadores de áudio online, que têm sido interpretados como capazes de impactar na frequência de uso e na complexidade de componentes envolvidos no desenvolvimento das habilidades orais de estudantes de inglês (HUANG, 2008; LYNCH, 2007; POP; TOMULETIU; DAVID, 2011; SONG, 2009; SUN, 2009).

Pop, Tomuletiu e David (2011) pesquisaram a integração de um fórum de gravação e interação de voz online ${ }^{6}$ para envolver estudantes em atividades orais de inglês após as aulas. Os autores (2011) demonstraram em seu estudo que os estudantes participantes da pesquisa se sentiram orgulhosos de ver suas contribuições na forma de postagens de arquivos de áudio nos fóruns e responderam positivamente às interações orais desenvolvidas no ambiente digital. Com o uso de blog de voz, sentimentos similares como de satisfação, confiança e alegria, que têm relação com uma sensação de realização e pertencimento, também foram relatados por Huang (2008). Outro resultado do estudo de Pop, Tomuletiu e David (2011) foi que os estudantes conseguiram encontrar, no fórum de voz, ambientes que preenchessem suas demandas específicas. Para os estudantes que os autores avaliaram estar entre o nível básico e pré-intermediário, a tecnologia assíncrona ajudou a preparar suas respostas e eles relataram redução no nível de ansiedade em comparação com interações face a face, quando se sentiam inferiores aos interlocutores considerados mais proficientes. Já os estudantes com maior nível de proficiência apreciaram os fóruns com temas

\footnotetext{
${ }^{5}$ A plataforma Vocaroo, por exemplo, permite a gravação de áudio e incorporação a blogs e ambientes de ensino/aprendizagem online. Voxopop, como fórum de voz online, e o Voki contam ainda com a possibilidade de construção de avatares digitais.

${ }^{6}$ Disponível em: <http://www.voxopop.com/>.
} 
e discussões presentes em exames internacionais de proficiência, como o TOEFL e o IELTS.

Lynch (2007) comparou o desenvolvimento do desempenho oral entre duas turmas. Em uma delas, o professor avaliou e deu retorno sobre as gravações orais dos estudantes e na outra turma os estudantes foram encorajados a elaborar uma autoavaliação a partir de suas gravações. A análise das gravações feitas ao final dos cursos indicou que a turma que se autoavaliou e transcreveu algumas de suas falas teve desempenho melhor em termos de acuidade gramatical e pronúncia. Entretanto, para Lynch (2007), outras pesquisas precisam ser realizadas para confirmar se esses processos de autoavaliação das gravações podem mesmo indicar maior acuidade na produção oral. Huang (2008) também fez uma pesquisa semelhante, com autoavalição de estudantes de inglês por meio de autotranscrição de suas falas, conversações e diálogos, mas não avaliou se houve melhora na pronúncia e nem se os estudantes verificaram seu próprio aperfeiçoamento na pronúncia. Vale ressaltar que a transcrição de gravações não é tarefa fácil sem o devido treinamento para avaliar desde a pronúncia das palavras, suas sílabas tônicas até características de ritmo e entonação na fala.

Sun (2009) pesquisou se o aumento na oportunidade de prática oral com blogs de voz melhorou o desenvolvimento de habilidades orais de 46 estudantes tailandeses universitários de inglês em um blog de voz. Eles postaram trinta textos com dez respostas interativas ao longo do semestre. Após análise de conteúdo e categorização de suas postagens, Sun (2009) sugere que os participantes da pesquisa melhoraram sua disposição para se comunicar. Além disso, a percepção dos estudantes sobre sua expressão oral também se tornou mais positiva. Os dados indicam que os estudantes processaram suas postagens orais com maior ensaio e preparação, além de afirmarem que as postagens no blog de voz ajudaram a melhorar suas habilidades orais e a baixar a ansiedade para se comunicarem em inglês. Um estudante afirmou que as tecnologias de comunicação assíncrona "realmente ajudaram a reduzir a inibição ao falar inglês" e outro destacou que "ao contrário do meu ambiente de sala de aula, blogs de voz me fizeram sentir relaxado com a possibilidade de poder preparar minha e fala e me sentir falando com mais fluência. Eu sinto que meu desempenho melhorou no blog de voz mais que em situações face a face” (SUN, 2009, p. 97).

Ao investigar o impacto de um diário de notícias orais na internet, o que se assemelha a um blog de voz, Song (2009) também argumenta que 
tecnologias de VOz assíncronas podem reduzir a ansiedade de estudantes. A pesquisa procura avaliar as percepções dos participantes acerca das atividades de postagem de textos orais durante dez semanas. Os resultados sugerem que os estudantes melhoraram o desempenho oral após comparação entre pré-testes e pós-testes. Os dados qualitativos indicaram que as atividades diminuíram a ansiedade e os estudantes relataram se sentirem mais confortáveis e naturais ao falar inglês.

Poza (2011) também procurou comparar a ansiedade em suporte digital de voz com interações face a face, usando para avaliação uma versão adaptada da escala de ansiedade de língua estrangeira (ALE). ${ }^{7}$ Por seis semanas, 48 estudantes de espanhol como língua estrangeira participaram do estudo completando atividades de discussão que demandavam respostas a perguntas e postagens feitas pelo professor e pelos alunos. Na análise dos dados, Poza (2011) encontrou poucas diferenças entre o nível de ansiedade nos contextos face a face e no ambiente com tecnologia de voz. Por outro lado, dados de entrevistas de quatro estudantes indicaram que eles se sentiram mais relaxados no contexto digital do que no contexto face a face da sala de aula. As razões foram apontadas como sendo, principalmente, o tempo que tinham para editar suas falas e a ausência física de interlocutores.

McNeil (2014) argumenta que pesquisas anteriores sugerem que os propiciamentos, ${ }^{8}$ ou aquilo que está potencialmente disponível para ação em ambientes de comunicação assíncrona mediada por computador, ajudam a reduzir a ansiedade de língua estrangeira. Entretanto, a ALE é raramente o foco desses estudos, e a pesquisa sobre a temática no contexto digital não tem respondido adequadamente acerca da relação entre ALE e a percepção de elementos nos ambientes de comunicação que podem detonar a ansiedade nos estudantes. McNeil (2014) explorou as fontes de ALE no ambiente de comunicação assíncrona mediada por computador e como as percepções para ação comunicativa dos estudantes no ambiente se correlacionavam com ALE. Uma turma de quinze universitários coreanos, estudantes de inglês, completou tarefas em um blog de voz por oito semanas.

\footnotetext{
${ }^{7}$ A ansiedade de língua estrangeira (ALE) é definida como o sentimento de tensão, desconforto e apreensão associada especificamente com contextos de ensino/aprendizagem de uma segunda língua (HORWITZ, 2001).

${ }^{8}$ O termo "propiciamento" foi traduzido por Paiva (2010) a partir de affordance, presente em Vanlier (2004).
} 
Dados das percepções dos estudantes foram coletados e a ALE foi medida qualitativamente por uma versão adaptada da escala de ALE (HORWITZ, 2001).

Os resultados de McNeil (2014) sugerem que os estudantes percebem as tecnologias assíncronas de modos particulares e que algumas fontes de ansiedade são similares àquelas relatadas em contextos face a face, embora outras sejam específicas ao ambiente de comunicação digital assíncrona. Os resultados confirmam estudos anteriores que indicam que estudantes podem sentir baixos níveis de ansiedade em interações orais com tecnologias assíncronas (POZA, 2011; SONG, 2009; SUN, 2009). Alguns estudantes perceberam que o tempo para preparação do texto oral e a ausência física de outros no ambiente, quando desempenhavam as tarefas, ajudaram a diminuir sua ansiedade para se expressarem em língua estrangeira com expressões como, por exemplo, "eu me senti mais confiante usando o gravador de voz online porque eu não tinha que falar em tempo real, porque não sou bom em improvisar e corrigir gramática e vocabulário". Ou mesmo por meio de afirmações como "não fico tão nervoso no Voxopop, porque não há uma audiência que está presente na minha frente quando falo inglês" (MCNEIL, 2014, p. 144-155).

Fóruns de voz compartilham características de gravadores de áudio que podem gerar ações relacionadas ao maior tempo para compreender o texto oral que solicita uma tarefa ou um retorno, refletir sobre a resposta, construir o texto, e editá-lo. Todas são ações que podem fortalecer habilidades de análise e conscientização linguística tanto em questões léxicogramaticais quanto em outras sub-habilidades da fala, como entonação, sílabas tônicas e prosódia (MCNEIL, 2014). Gravadores de voz online ainda permitem o uso de dicionários e scripts para gravar seu texto oral. Assim, o estudo indica que a percepção e ação dos estudantes com as tecnologias assíncronas têm potencial para reduzir a ansiedade de expressão em língua estrangeira (MCNEIL, 2014). McNeil (2014) também encontrou indicações de que as tecnologias assíncronas de voz não eliminam a ALE automaticamente. Para explicar esse resultado, foi apresentado o argumento de que as habilidades, a tarefa e a interpretação do ambiente pelos estudantes funcionaram de maneira articulada para produzir ou diminuir o nível de ansiedade em língua estrangeira.

Conforme apontei na seção anterior, se o início da pesquisa sobre as emoções no ensino/aprendizagem de línguas foi marcado pelo foco 
na correlação entre construtos afetivos e resultados de aprendizagem em níveis de proficiência (GARDNER; MACINTYRE, 1993; SCOVEL, 1978; PAVLENKO, 2013), com a motivação e a ansiedade sendo as principais variáveis, podemos notar hoje uma continuidade dessa tradição nos estudos revisados acerca do desenvolvimento de habilidades orais com tecnologias digitais assíncronas. Notamos que no âmbito da aprendizagem de línguas mediada por computador, a variável afetiva mais investigada tem sido a ansiedade. Aqui se pode reiterar a crítica já feita por outros autores sobre essa recorrência teórico/metodológica na pesquisa sobre os aspectos emocionais no ensino/aprendizagem de línguas (ARAGÃO, 2011; BARCELOS, 2015; NORTON, 2013; PAVLENKO, 2013).

O termo "variável afetiva" desloca nosso foco do aprendiz - foco esse que pressupõe que o fenômeno ocorre em uma mente individual, assim dificultando sua compreensão da dinâmica processual - para as relações e posicionamentos desse aprendiz no processo de interação (ARAGÃO, 2011; PAVLENKO, 2013). Nessa esteira, notam-se lacunas nos estudos revisados por não apontarem as inter-relações entre contextos, sujeitos e seus efeitos nas ações e relações de estudantes e professores. Ainda se observa que outras emoções que possam embasar as ações de estudantes ou professores podem não ser pesquisadas, se o foco recai sempre na ansiedade ou na motivação. Crítica similar é feita por Pavlenko (2013), ao argumentar que o paradigma da dimensão afetiva exauriu seu limitado potencial explicativo.

$\mathrm{Na}$ seção que segue descrevo a metodologia da pesquisa, bem como faço a discussão dos dados coletados. Para responder às perguntas norteadoras da pesquisa, indico os sentimentos mais comuns destacados pelos participantes em dois grupos: segurança e confiança e medo e ansiedade.

\section{Metodologia e discussão dos dados}

Esta é uma pesquisa de cunho qualitativo e de base experiencial, ou seja, pesquisa que enfoca a experiência daqueles que vivenciam o fenômeno do ensino/aprendizagem. Através da perspectiva dos participantes, temos acesso à complexidade desse fenômeno (ARAGÃO, 2008; MICCOLI, 2010). Esta pesquisa experiencial pode auxiliar, por exemplo, a alargar nosso entendimento sobre o ensino e aprendizagem de línguas a partir do ponto de vista daqueles que vivem a experiência situada na prática. Além disso, reitera o valor atribuído à reflexão sobre as experiências para o agenciamento 
consciente da prática a partir dos sentidos que emergem na reflexão sobre a experiência.

Os instrumentos de coleta de dados estão voltados para o registro de informações que fornecem acesso à experiência da aprendizagem e à observação dessa experiência na prática. Como indicado na introdução, o trabalho foi desenvolvido durante a primeira etapa de uma formação de professores de inglês para uso de tecnologias digitais móveis entre outubro e dezembro de 2015. A formação e a pesquisa foram realizadas na plataforma WhatsApp por meio de um grupo constituído com todos os participantes, foi desenvolvida com nove professores participantes do primeiro módulo dessa formação continuada. Os professores moram em diferentes cidades do estado de Minas Gerais, da Bahia, e da Paraíba. Sete participantes são professoras de escolas públicas e dois professores atuam em escolas públicas e privadas e no ensino superior. Todos os participantes assinaram um termo de consentimento livre e esclarecido para a pesquisa e todos são indicados no estudo com uso de pseudônimos.

A coleta de dados envolveu observação-participante no ambiente do curso com captura de telas de todas as interações, um questionário online, uma entrevista semiestruturada e a coleta de imagens que representassem o sentimento sobre o desenvolvimento das habilidades orais no contexto do WhatsApp. As perguntas no questionário, que foram aprofundadas na entrevista e na coleta de imagens, foram: Como você se sentiu ao usar o recurso de áudio para falar inglês no WhatsApp? Descreva uma emoção que foi mais presente ao falar inglês no WhatsApp. O fato de as mensagens de áudio serem feitas via WhatsApp te deixou mais à vontade do que em um encontro presencial? As entrevistas semiestruturadas foram feitas por meio do próprio recurso de gravação de áudio do WhatsApp com base nas respostas à pergunta feita no questionário sobre como se sentiram ao realizar as atividades feitas no primeiro módulo do curso de formação continuada móvel. As entrevistas foram também fundamentadas no registro e observação das interações desenvolvidas durante o curso, seguindo protocolo adaptado de Aragão (2011). Com relação à coleta de imagens, logo após a realização do questionário e da entrevista semiestruturada, os participantes foram solicitados, por meio das perguntas de pesquisa, a escolher imagens que melhor representassem seus sentimentos na experiência da pesquisa, seguido de um breve texto que explicasse a imagem enviada. Embora tenha sido solicitada uma imagem, todos os participantes espontaneamente enviarem um meme. 
Os participantes do curso realizaram uma série de atividades que incorporavam o conceito de aprendiz móvel com tecnologia móvel (PEGRUM, 2014). ${ }^{9}$ Foram realizadas atividades com uso de mensagens de textos escritos e orais, compartilhamento de fotos e de localização dos participantes no ato da atividade. Objetivou-se trabalhar os gêneros comuns no WhatsApp, como os memes, as selfies, os mapas com fotos de locais em que os participantes se encontravam. Dentre as atividades podemos destacar a postagem de arquivo de áudio comentando um vídeo sobre a importância da tecnologia no ensino de línguas; a produção de selfies com textos; a produção de memes e a eleição do melhor meme por meio da postagem com a justificativa em áudio; um arquivo de áudio indicando o que estava fazendo através da postagem com a descrição de onde estava.

O ambiente das atividades foi um aplicativo de smartphone ligado à mobilidade digital. O WhatsApp é um aplicativo de mensagens instantâneas multimodais que, se conectado à internet, torna possível a troca de mensagens pelo smartphone, sem o custo de um SMS. Nesse aplicativo, é possível criar grupos com a adição de contatos na agenda telefônica do usuário e de outros usuários que dispõem do mesmo aplicativo. O WhatsApp é convergente com outros aplicativos disponíveis no aparelho para gravação e edição de áudio, gravação e edição de vídeo e fotos.

Os dados qualitativos foram organizados em torno de padrões de reações ao uso das ferramentas e a percepção das emoções, tais como a expressão de sentimentos avaliados como positivos e negativos pelos participantes. A análise propõe que padrões, temas ou categorias de experiências que representem as emoções sejam identificados durante o período de pesquisa e durante a leitura/interpretação dos dados coletados (ARAGÃO, 2008; MICCOLI, 2010). Minha interpretação foi realizada com fragmentos dos discursos dos participantes indicando o padrão de uma determinada emoção. Analisei os dados coletados de cada estudantevoluntário a fim de verificar a influência das emoções no desenvolvimento de suas habilidades orais. Temas recorrentes em unidades de significado foram agrupados para que pudessem ser identificados como comuns aos participantes ou particulares de cada um (ARAGÃO, 2011; ARAGÃO;

\footnotetext{
${ }^{9}$ Braga (manuscrito) apoiada em Pegrum (2014), afirma que a aprendizagem móvel, nesse nível, engloba o dispositivo, o aprendiz e a aprendizagem, todos em conjunto, de forma que a proposta de aprendizagem transforma diferentes contextos reais em contextos de aprendizagem.
} 
DIAS, 2016). No que segue faço a discussão dos dados coletados na pesquisa.

\subsection{A segurança e a confiança}

Quatro professoras relataram sentimentos associados ao aumento da confiança para falar inglês usando o dispositivo de gravação de áudio do WhatsApp. A prof ${ }^{a}$. Fernanda relatou, por exemplo, que se sentiu "um pouco inibida no início", mas à medida que interagia "foi positivo ir arriscando, pois, a segurança foi aumentando no decorrer das atividades". Para a professora, o sentimento de segurança ao falar inglês foi aumentado pela "possibilidade de podermos gravar e se ficar ruim, fazer de novo, isso vai dando mais segurança". Além disso, ela relatou que, com a possibilidade de gravar novamente, tendo tempo disponível para refletir sobre o áudio, ela ganhava mais confiança na produção do texto. Quando questionada se o fato de as mensagens de áudio serem feitas via WhatsApp lhe deixou mais à vontade do que em um encontro presencial, ela respondeu no questionário que "com certeza" e durante a entrevista, aprofundou:

Eu acredito que o aplicativo é menos constrangedor que o cara a cara, pois não tem um feedback logo da fisionomia da pessoa, você não pensa logo sobre o que o outro está pensando. Então você até pensa, mas depois. E aí vai, com isso, a gente vai conseguindo fluir mais com o inglês, pois você não tem o feedback imediato da expressão do outro. (FERNANDA, comunicação pessoal)

Notem que a ausência de indicadores corporais dos interlocutores, que tendem a fazer com que o outro se sinta inibido e desautorizado a se expressar (SULLER, 2004), bem como a ausência de uma audiência física e psíquica julgadora (MCNEIL, 2014), parecem ter influenciado para que a professora Fernanda "fosse fluindo mais com o inglês". Ela ainda avaliou a experiência como positiva, gratificante e importante para seu aprendizado. Esses sentimentos foram representados pela imagem que segue: 
FIGURA 01: Fernanda descreve seu sentimento positivo com a experiência

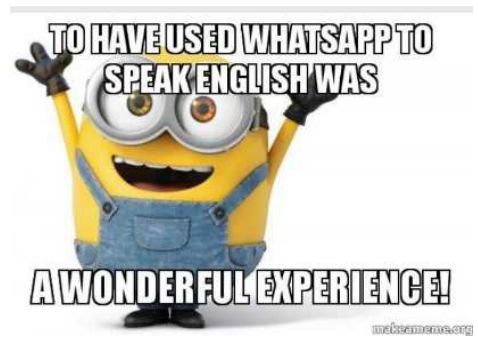

Observação similar foi feita pela professora Kátia ao descrever o sentimento predominante ao falar inglês por meio de arquivos de áudio do WhatsApp:

Sempre tive dificuldade ao falar inglês. Acho que não tenho uma pronúncia muito boa. Falo sempre para meus alunos que $80 \%$ do que sei, aprendi sozinha. Mas, como não tem ninguém observando, mas só ouvindo, me senti mais segura para falar e isso foi muito bom! (KÁTIA, comunicação pessoal).

Durante a entrevista, a professora Kátia reiterou as dificuldades que sempre teve para falar inglês. Relatou que não julgava ter boa pronúncia, mas como não tinha ninguém observando, ela falou inglês do jeito dela, "sem muita preocupação". Notem aqui novamente um relato similar a participantes da pesquisa de McNeil (2014) e Poza (2011) com relação à ausência de uma audiência intimidadora. Kátia foi a participante que mais se referiu a essa experiência como marcante e positiva em seus cursos de formação continuada. Segundo a professora, ao postar os arquivos de áudio, ela "se sentiu mais confiante para falar e participar de todas as atividades". Kátia se sentiu realizada e orgulhosa com a possibilidade de escutar a si mesma junto do grupo de colegas professoras e perceber-se capaz de fazê-lo. Vejam como ela se refere a esse processo no excerto que segue, coletado da entrevista. Na sequência, ela representa esse sentimento por meio de uma imagem e da fala que descreve a imagem, que foi feita em inglês.

Olha, Rodrigo, eu colocava o áudio das colegas mais de uma vez para eu entender, tipo prática de listening. Mas quando eu postava e escutava meu próprio áudio, eu falava: gente, eu falei, que legal !!! [risos] É lógico, a gente se sente assim é... um sentimento bom, gostoso, a gente conseguir falar, que legal conseguir participar e 
quando os colegas retornavam, eu me senti muito bem. Olha que bacana e você se sente realmente mais confiante porque você teve condição de participar de um grupo onde a maioria consegue se expressar melhor do que eu e eu consegui participar desse grupo. Me sinto bem agora. Pessoalmente, não me sinto inibida, escutava eu mesmo falando e colocava para os meus filhos escutarem e me sentia orgulhosa disso. E me senti bem em saber que sou capaz. E no momento que consegui participar de um grupo bom e participar é um sentimento muito bom. (KÁTIA, comunicação pessoal).

FIGURA 02: Kátia expressa sua confiança ao falar inglês nas atividades do projeto

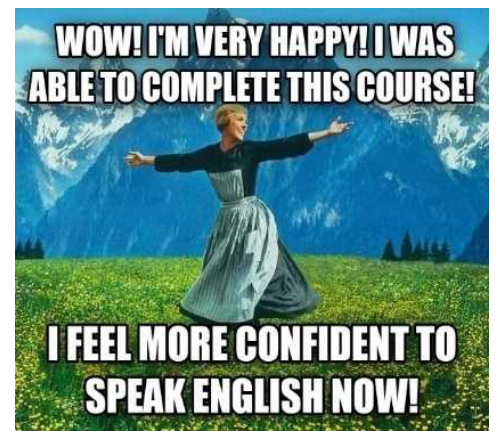

O que posso falar sobre esse meme é o seguinte: I will speak in English ok? This meme reflects my sense of joy and achievement. Participating in this course, I had the opportunity to express myself in English with more time and more quietly, because I knew no one was watching me. This is like to climb a big mountain and express to all the people my happiness. (KÁTIA, comunicação pessoal). ${ }^{10}$

A professora Patrícia respondeu ao questionário dizendo que os sentimentos que predominaram foram a segurança, o conforto e a tranquilidade de poder falar inglês com mais facilidade pelo áudio do WhatsApp. Ela sente falta de oportunidades para falar inglês e desenvolver

\footnotetext{
${ }^{10}$ Minha tradução: Vou falar em inglês, ok? Esse meme reflete minha sensação de alegria e realização. Ao participar desse curso, eu tive a oportunidade de me expressar em inglês com mais tempo e mais tranquilamente, porque eu sabia que ninguém me observava. Isso é como escalar uma grande montanha e expressar minha felicidade para todos.
} 
seu conhecimento na língua que ensina. Ao solicitar que ela discorresse mais acerca dos sentimentos vividos no curso, ela comentou:

Para as pessoas que são um pouco tímidas igual a mim, falar no áudio é mais fácil e mais confortável. E você falar cara a cara, você precisa ter uma segurança maior, assim, para comunicar, igual [a] trabalhos em sala de aula, uns alunos meus muito tímidos apresentaram um trabalho em forma de fantoches. Então os fantoches eram os personagens e eu acredito que quando você tem uma certa timidez e tem a oportunidade de falar em áudio é mais fácil. Isso fica mais tranquilo do que quando você está cara a cara com a pessoa. (PATRÍCIA, comunicação pessoal).

A professora Ana Liz também comentou, tanto no questionário quanto na entrevista, que se sentiu "mais segura", "mais firme" para falar inglês pelo WhatsApp. Mesmo sabendo que a turma era "altamente capacitada", ela se sentiu menos inibida para interagir pelos arquivos de áudio do WhatsApp.

O caso da professora Kátia parece corroborar com resultados apresentados por Pop, Tomuletiu e David (2011), que indicam que os estudantes participantes da pesquisa se sentiram orgulhosos em ver suas contribuições na forma de postagens de arquivos de áudio nos fóruns e responderam positivamente às interações orais desenvolvidas no ambiente digital. Sentimentos similares, como satisfação, confiança e alegria, que têm relação com uma sensação de pertencimento, também foram relatados por Huang (2008).

Os sentimentos das professoras Fernanda, Kátia, Patrícia e Ana Liz somam-se aos sentimentos de outros participantes de estudos revisados neste artigo, que indicam maior segurança, conforto e menor inibição para falar inglês com tecnologias digitais assíncronas (MCNEIL, 2014; POZA, 2011; SONG, 2009; SUN, 2009).

A emoção da confiança para o uso oral da língua é fundamental para embasar disposições comunicativas, nas palavras dos participantes: "seguras" e "firmes". Observamos que tanto em contexto de sala de aula quanto usando tecnologias digitais, os estudantes reiteram a importância de estarem imersos em um espaço que se sintam seguros e confiantes para falar inglês. A emoção da confiança para falar inglês é comum ao processo de desenvolvimento de habilidades orais, independentemente de contextos e tecnologias (ALASTUEY, 2011; ARAGÃO; DIAS, 2016; MICCOLI, 
2010; NORTON, 2013; REINDERS; WATTANA, 2014; 2015; YANGUAS; FLORES, 2014). Isso contrasta com os estudos revisados na seção anterior sobre emoções e tecnologias, em que a ansiedade permanece a emoção mais pesquisada.

\subsection{0 medo e a ansiedade}

Outro grupo, composto por cinco participantes, relatou um sentimento de insegurança com o uso do recurso de gravação de voz do WhatsApp, referindo-se recorrentemente a ele com a expressão "medo de errar". Como veremos, esse sentimento parece estar associado com as características do recurso de gravação de áudio do WhatsApp. A professora Graça fez o seguinte comentário, em resposta à pergunta sobre se teria ficado mais à vontade para falar inglês com os arquivos de áudio: "fiquei mesmo apreensiva em gravar os áudios. Tive receio de errar (assim como meus alunos) rs, rs". Assim como Graça, a professora Flávia registrou no questionário que os sentimentos que predominaram ao falar inglês com o recurso de gravação de foram a ansiedade e o medo de errar. Ela comentou que não tem como se corrigir com o recurso de gravação de áudio do WhatsApp e que há muita avaliação no grupo, e por isso também se sentia ansiosa para falar. Ao ser perguntada acerca das razões desse medo, ela respondeu:

Porque uma vez que a gente está escrevendo, a gente tem como redigir ou verificar se está acertando ou errando antes de publicar. Já no áudio do WhatsApp a gente tem menos tempo, daí esse falar no WhatsApp traz a ansiedade por não ter tempo de pensar raciocinar e me foge as palavras. Uma vez que a gente está no grupo, a gente se expõe e a gente quer fazer o melhor e quer se esforçar. O falar cara a cara não intimida, mas no grupo eles estão de certa forma avaliando o que está sendo feito e no cara a cara tem menos avaliação. (FLÁVIA, comunicação pessoal).

Notem como a percepção de Flávia é distinta do grupo anterior, que relatou mais conforto e segurança para falar inglês com o recurso de áudio do que em contextos face a face. A professora Graça também reporta um sentimento de avaliação julgadora com a audiência do grupo: "É assim, Rodrigo, quando tem áudio e tem várias pessoas e tem gente que também tem dificuldade e outras são mais fluentes e tem esse medo que a gente quer vencer. O medo quando vai gravar então é um desafio que eu quero vencer”. 
Entretanto, diferentemente de Flávia, a professora Graça sugere, tanto no questionário quanto na entrevista, que o sentimento ao falar inglês no curso era que ela precisava correr riscos para superar seus medos - enfatizando que pretende vencê-los. Graça interpretava as oportunidades de interação oral pelo WhatsApp como uma maneira de superar seu medo de falar inglês. Vejam como ela representa essa emoção de vencer o medo:

FIGURA 03: Graça representa seu desejo de correr riscos e superar seus medos

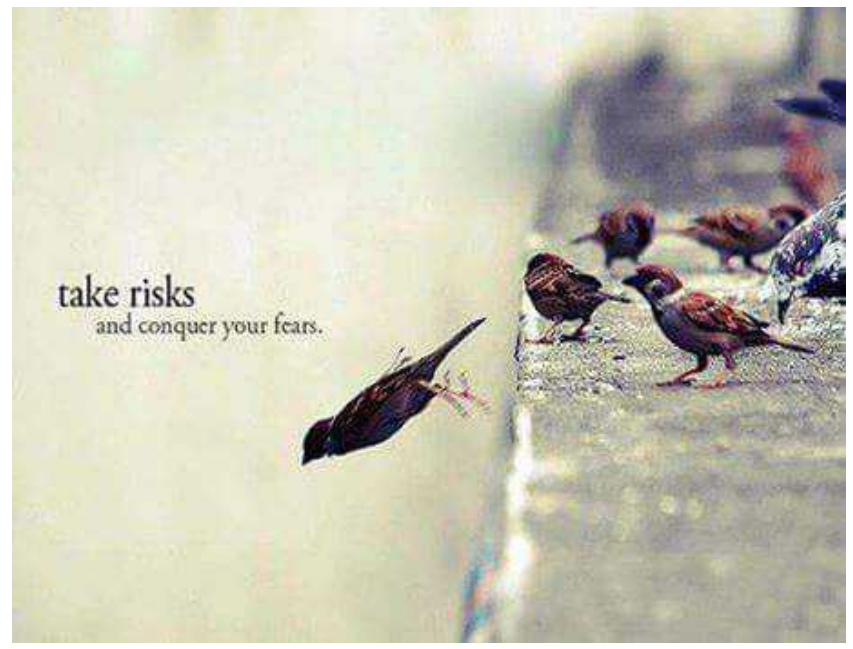

Para Flávia, a impossibilidade de verificar se seu texto está certo antes de enviar lhe causava um medo de errar. Deixar esse arquivo de áudio registrado e circulando no grupo, desencadearia esse medo de falar inglês usando o recurso de gravação de áudio do WhatsApp. Flávia utilizava somente o recurso de gravação em tempo real do WhatsApp e desconhecia que havia a possibilidade de gravar o áudio pelo recurso integrado do smartphone, que, nesse caso, poderia ser escutado, avaliado, ensaiado e editado, antes do envio. João, Ana Carolina e Renato também relataram insegurança por medo de errar e os possíveis erros ficarem registrados no arquivo de áudio, aos quais todos teriam acesso, a qualquer hora e quantas vezes os colegas do grupo quisessem escutar. João, por exemplo, comentou no questionário que o sentimento que predominou foi a insegurança "por poder estar falando errado ou um inglês com um vocabulário muito básico”. $\mathrm{Na}$ entrevista ele aprofundou e disse que "o fato de ser um registro que vai 
ficar salvo no celular de várias pessoas, eu acho que foi isso que provocou a insegurança". Já a professora Ana Carolina relatou que a emoção que predominou foi a tristeza "porque a minha voz saiu horrível e eu odeio escutar minha voz gravada".

Com sentimento de "nervoso" predominante nas atividades orais, o professor Renato comentou na entrevista e em sua imagem que:

Quando teve logo a primeira atividade que tive que mandar um áudio, eu me senti nervoso porque não sei, mas quando falo, assim, normalmente, na aula ou em um concurso, é tranquilo, mas por ser a ferramenta que permite reexecutarem sua voz, eu fiquei nervoso pela possibilidade de reescutarem meu áudio. Isso significa maior possibilidade de notar um erro de língua na minha fala. Erro de língua, sabe? Não havia parado para pensar sobre isso antes, mas talvez por ser um grupo também que ainda não tinha senso de comunidade e eu não conhecia ninguém então me sentia tão ansioso e nervoso. (RENATO, comunicação pessoal).

FIGURA 04: Renato representa sua ansiedade ao falar inglês no WhatsApp

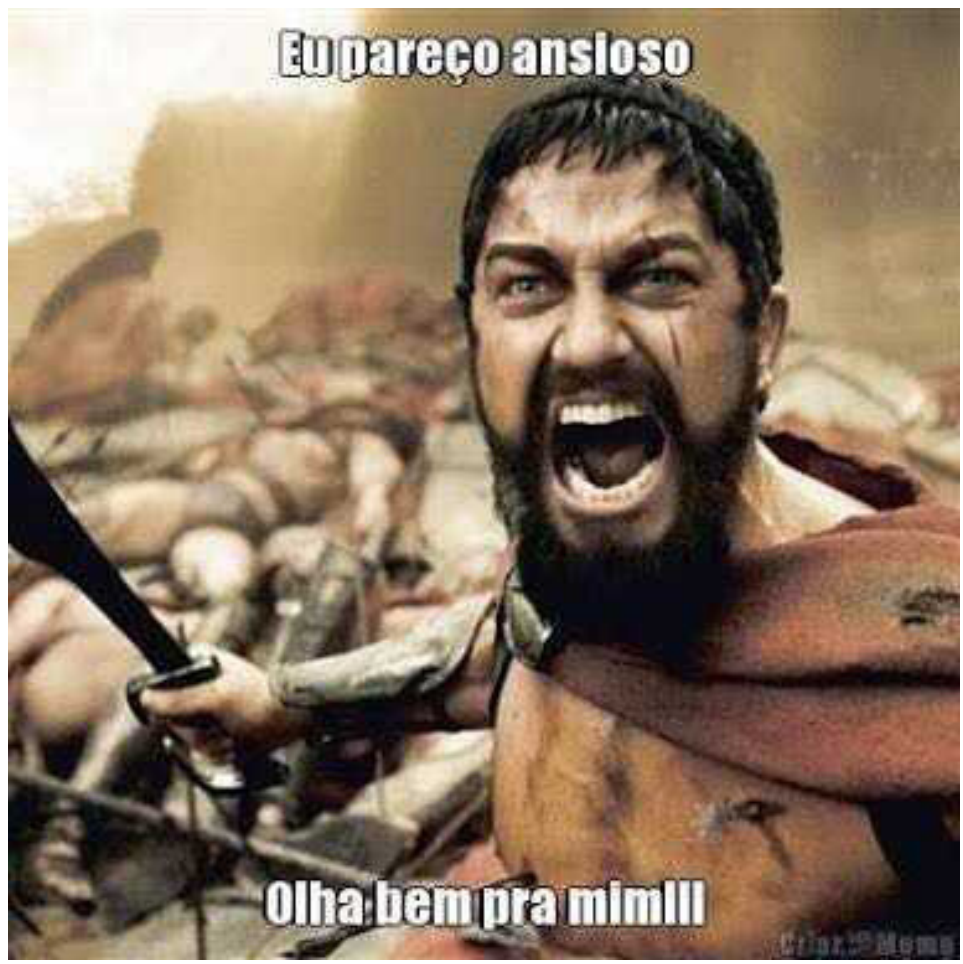


Portanto, podemos concluir que, para esses cinco participantes, a tecnologia de gravação da voz e a possibilidade de registro desse arquivoque poderia ser objeto de observação, escrutínio e avaliação pelos colegas - levou ao aumento no nível de insegurança e ansiedade na expressão oral em inglês no aplicativo. Nesse sentido, esses resultados corroboram com os dados de McNeil (2014), que documentou o aumento no nível de ansiedade quando há recorrente escuta da voz de outros colegas pela tecnologia.

Um dado interessante, entretanto, tem relação com o que o professor João comentou no questionário, inicialmente. Ao perguntar se o fato de as mensagens de áudio serem feitas via WhatsApp o teriam deixado mais à vontade do que em um encontro presencial, o professor disse: "Não tenho certeza. Acho que a possibilidade de regravar me deixou mais ansioso em buscar a perfeição". Na entrevista, solicitei que falasse mais sobre isso e ele me disse que "a possibilidade de poder regravar também motiva a busca pela perfeição. Ouvir a própria pronúncia e perceber problemas provoca um pouco dessa insegurança, mas motiva a buscar essa perfeição e melhorar a fala". João, ao refletir sobre como suas emoções influenciam suas interações e vice-versa, nos mostra que a ansiedade vivida por ele pode ser distinguida como um tipo de ansiedade positiva (SCOVEL, 1978). Nesse sentido, se por um lado o registro de sua voz parece lhe causar insegurança e ansiedade, por outro, essas emoções podem lhe mover a aperfeiçoar seu texto e se tornar mais consciente de sua produção oral.

Nota-se na literatura que alguns estudantes avaliam as tarefas orais em contexto digital como mais exigentes que nas interações face a face. Isso parece, também, levá-los a realizar mais interações reparadoras, com autocorreção e edição de suas produções, mesmo com o uso de recursos de apoio para essa preparação e edição. Talvez ainda, a ausência de elementos visuais possa levar a um trabalho mais exigente na interação com tecnologias digitais de áudio, em que a imagem do interlocutor não esteja disponível. Há uma indicação na literatura que os estudantes processam suas postagens com maior planejamento, ensaio e avaliação (SONG, 2009; HUANG, 2008). Sobre esta última ação inclusive, ainda não sabemos de maneira mais aprofundada o que ocorre e porque ocorre a escuta recorrente de suas próprias gravações, antes e depois de feitas as postagens. Em outras perguntas do questionário, em que se perguntava acerca disso, muitos relataram que buscavam escutar os colegas por curiosidade. 
Observo aqui neste caso que João parecia buscar aperfeiçoar sua fala por meio de escuta recorrente, edição e postagens novas. Entretanto, não foi investigado como isso é feito nem que detalhamentos linguísticos são observados. Indica-se aprofundamento nessa questão na continuidade da pesquisa, assim como já sugere a literatura revisada. Com relação a pesquisas que usam sessões de visionamento, em que se observa gravações em vídeo de comportamentos de professores em sala de aula, temos resultados positivos quando os participantes se veem e passam a se autoperceber, transformando autoavaliações negativas (ARAGÃO, 2008; MICCOLI, 2010).

A questão do tempo para poder trabalhar o texto oral assim como a possibilidade de fazer isso no tempo e horários mais tranquilos e confortáveis para cada um também foram pontos positivos mencionados pelos participantes e que podem ser aprofundados e articulados a perspectivas de pesquisa em MALL.

\section{Implicações e considerações}

A partir dos resultados parciais dessa pesquisa em andamento, pode-se observar que a percepção sobre a própria fala no WhatsApp toma contornos particulares e sentidos diversos para os participantes, como indicado também no estudo de McNeil (2014). Identificou-se um grupo que se sentiu mais seguro e menos inibido para falar por meio da gravação de áudio do WhatsApp do que em contextos face a face, o que corrobora com outros estudos com tecnologias assíncronas (POZA, 2011; SONG, 2009; SUN, 2009). Por outro lado, um grupo relatou sentir-se mais inseguro, ansioso e com medo de errar ao usar um recurso que grava sua voz e a registra para observação, em qualquer tempo e qualquer lugar pelos colegas do grupo. Os participantes desse grupo também se sentiram movidos por essa ansiedade a aperfeiçoarem seu texto oral e a buscar mais oportunidades de fala à medida que observavam lacunas e pontos fracos a serem trabalhados em suas produções. Um dos participantes inclusive relatou que esse medo de errar detonava a busca por maior perfeição na fala. Notem aqui como a emoção da ansiedade, comumente considerada como negativa pela literatura da área (HORWITZ, 2001), é interpretada com impactos positivos para o aperfeiçoamento das habilidades orais de alguns participantes da pesquisa.

A emoção não pode ser entendida aqui como algo dado, seja este interno ou externo; tampouco esse fenômeno pode ser dissociado de uma gama de elementos socioculturais, de experiências prévias, de 
posicionamentos identitários e processos de produção de sentidos pelas pessoas, que se desenvolvem de maneiras interdependentes. A ansiedade pode ser mais bem compreendida em sua perspectiva situada e como ela é detonada ou detona ações e relações em jogos de mútua constituição. Como Norton (2013) tem indicado, por exemplo, emoções como a ansiedade e a motivação não devem ser compreendidas como características individuais daqueles que aprendem ou ensinam uma língua, ou mesmo como fatores externos do ambiente que por si só possam determinar o que ocorre nos sistemas de ensino/aprendizagem.

Sentimentos de segurança e realização na participação do projeto também foram relatados com frequência por um grupo de participantes. Observem que os professores do projeto residem em diferentes cidades e estados e que a tecnologia nos proporcionou o desenvolvimento de um projeto em qualquer tempo e lugar. Vejo potencialidades de usarmos essa tecnologia para a criação de redes estruturadas em que professores possam lidar com sentimentos de isolamento, solidão, desemparo, insegurança, desinteresse e frustração vividos no cotidiano da profissão e comumente relatados em pesquisas sobre formação continuada de professores (COELHO, 2011; CELANI, 2010; DUTRA; MELO, 2009; PAIVA, 2006; MICCOLI, 2010; REZENDE, 2014).

Quanto ao trabalho de edição de textos orais e de análise linguística, avalia-se, por exemplo, que tarefas de autotranscrição dos textos orais podem beneficiar os participantes de atividades mediadas por tecnologias digitais assíncronas. Penso que um trabalho linguístico pode ser feito aqui com foco na pronúncia, prosódia e entonação e na acuidade gramatical. Essas atividades podem estar alinhadas com uma perspectiva de conscientização metalinguística sobre a língua em uso. Conforme Dutra e Melo (2009) apontam com relação ao desenvolvimento de ações em projetos de formação continuada, o enfoque consciente em questões de precisão e acuidade linguística pode impactar positivamente no desenvolvimento profissional de professores.

O aprofundamento na reflexão consciente sobre aspectos linguísticos da produção de textos orais poderá reverberar na confiança dos professores quanto à capacidade de uso oral da língua. Essas implicações sobre o conhecimento da língua se relacionam a emoções de segurança e autoconfiança com implicações para construção de uma imagem positiva de falante da língua. Emoções se inter-relacionam às ações, crenças e 
identidades situadas em contextos de ensino/aprendizagem (BARCELOS, 2015). Emoção e ação interagem dinamicamente no desenvolvimento de habilidades linguísticas. Acredito que essa questão merece aprofundamento com mais pesquisa e desdobramentos práticos que apoiem os professores em formação inicial e continuada a potencializarem o desenvolvimento de seus textos orais. Assim, sugere-se que a pesquisa ainda precisa se aprofundar em relação ao impacto da autorreflexão sobre o desenvolvimento linguístico dos participantes a partir dos textos gravados de si mesmos e de colegas.

Ainda, gravarem a si mesmos, fora do ambiente da sala de aula, pode oferecer oportunidades produtivas. Foi relatado pelos participantes que isso tende a modificar emoções e ações sobre o contexto de uso da língua. Essas mudanças contextuais podem deixar os estudantes mais confortáveis, sem ter ninguém os observando, como foi expresso, por exemplo, pela professora Kátia. Observo aqui que as atividades da formação continuada com o conceito de aprendiz móvel com tecnologia móvel (PEGRUM, 2014) apresentam potenciais interessantes para projetos de formação continuada de professores de inglês. Nesse sentido, os recursos oferecidos pelo WhatsApp oferecem potencial para o desenvolvimento das habilidades orais, o que pode, por sua vez, influenciar práticas de ensino/aprendizagem em seus contextos de trabalho.

Textos preparados também podem fortalecer a construção de gêneros textuais mais complexos e que demandam maior esforço de produção. Muito embora o compartilhamento de arquivos de áudio com outros colegas possa gerar ansiedade para alguns, por outro lado a mesma ação pode proporcionar experiências e emoções que são interpretadas como positivas para outros. Com turmas grandes e/ou em projetos de formação contínua com foco no desenvolvimento de habilidades orais, a mesmas estratégias usadas em sala de aula com o trabalho em pares ou grupos pequenos pode ser utilizada com o WhatsApp, fazendo que determinados arquivos possam circular em grupos menores. Nesse sentido, teríamos maior tempo para interação entre grupos menores, bem como redução do nível de ansiedade, já que a quantidade de pessoas que potencialmente possam avaliar os textos orais é menor.

O WhatsApp, enquanto uma tecnologia digital de voz assíncrona, pode ampliar potencialmente os espaços e tempos dedicados ao desenvolvimento das habilidades orais. Acredito que o uso dessa tecnologia pode fortalecer uma área que é muito demandada por professores de inglês em serviço. 
O desejo de falar fluentemente inglês é reportado nas pesquisas sobre a memória de professores de inglês em suas narrativas por Paiva (2006), bem como por Telles (2004). Assim, estratégias de desenvolvimento de habilidades orais com tecnologias digitais móveis podem influenciar positivamente projetos de formação continuada de professores de inglês.

É bom lembrar também que com o uso desse tipo de tecnologia, os tempos dedicados à interação se alargam, e surgem diversas oportunidades de autorreflexão e trabalho colaborativo. Há também possibilidades para o desenvolvimento de habilidades acadêmicas que podem inclusive causar impacto na interpretação crítica sobre o uso de recursos digitais a serem usados na escola. Alguns professores relataram como a participação na formação continuada os ajudaram a conversar com a direção de suas escolas com o objetivo de trabalhar pedagogicamente com a ferramenta. Nesse sentido, os participantes expressam indícios para lidar com os dilemas de seus contextos que pró́bem o uso de tecnologias móveis na escola. Entretanto, nessa etapa da pesquisa não foi possível aprofundar esse tema que surgiu na análise dos dados.

Penso que o impacto da apropriação das tecnologias e suas estratégias de ensino/aprendizagem no domínio de suas práticas pedagógicas possa ser um foco de estudos próximos no andamento do projeto. Avalio, por exemplo, a apropriação da linguagem dos memes representada nas imagens que expressam as emoções de segurança, confiança e ansiedade como indicadores positivos de emoções e ações para maior aprofundamento na continuidade da pesquisa.

\section{Agradecimentos}

Gostaria de agradecer a Vera Menezes e Júnia Braga todas as sugestões feitas ao longo da edição da primeira versão deste artigo. Agradeço aos participantes que colaboraram com o estudo bem como toda a equipe da Taba Eletrônica coordenado por Júnia Braga. Meus agradecimentos aos pareceristas anônimos pelas valiosas observações e sugestões que me orientaram no aperfeiçoamento desse artigo, bem como a Zelina Beato pela revisão na versão final do artigo. O presente trabalho foi realizado com bolsa do CNPq, Conselho Nacional de Desenvolvimento Científico e Tecnológico - Brasil (Processo 168419/2014-9) durante residência pós-doutoral no PosLin/UFMG sob a supervisão de Vera Menezes de Oliveira e Paiva, aos quais agradeço o apoio. 


\section{Referências}

ALASTUEY, M. C. B. Perceived benefits and drawbacks of synchronous voicebased system: the students' perspective. Computer Assisted Language Learning, v. 24, n. 5, p. 419-431, 2011.

ARAGÃO, R. Emoções e Pesquisa Narrativa: transformando experiências de aprendizagem. Revista Brasileira de Linguística Aplicada, Belo Horizonte, v. 8, n. 2, p. 295-320, 2008. Disponível em: < http://www.scielo.br/pdf/rbla/v8n2/03.pdf>. Acesso em: 2 fev. 2016.

ARAGÃO, R. Beliefs and emotions in foreign language learning. System, Linköping, v. 39, n. 3, p. 302-313, 2011. DOI: http://dx.doi.org/10.1016/j.system.2011.07.003. Acesso em: 2 fev. 2016.

ARAGÃO, R.; DIAS, I. A. Facebook e emoções de estudantes no uso de inglês. In: ARAÚJO, J.; LEFFA, V. (Org.). Redes sociais e ensino de línguas: o que temos de aprender? São Paulo: Parábola Editorial, 2016. p. 111-118.

BARCELOS, A. M. F. Unveiling the relationship between language learning beliefs, emotions, and identities. SSLLT, Kalisz, v. 5, n. 2, p. 301-325, 2015. Disponível em: <http://www.ssllt.amu.edu.pl/images/vol.5.no.2/SSLLT\%205(2)\%20301325\%20Ferreira\%20Barcelos.pdf>. Acesso em: 18 set. 2015.

BOSDOGAN, D. Mall Revisited: current trends and pedagogical implications. Procedia - Social and Behavioral Sciences, v. 195, p. 932-935, 2015. DOI: http:/ / dx.doi. org/10.1016/j.sbspro.2015.06.373. Acesso em: 05 jan. 2016.

BRASIL. Orientações Curriculares para o Ensino Médio: linguagens, códigos e suas tecnologias. Secretaria de Educação Básica. Brasília: Ministério da Educação, 2006.

BURSTON, J. MALL: the pedagogical challenges. Computer Assisted Language Learning, Amsterdam, v. 27, n. 4, p. 344-357, 2014.

BURSTON, J. Twenty years of MALL project implementation: A meta-analysis of learning outcomes. ReCALL, Cambridge, UK, n. 27, p. 4-20, 2015. DOI: http:// dx.doi.org/10.1017/S0958344014000159. Acesso em: 02 de fev. 2016.

CELANI, M. A. A. Perguntas ainda sem resposta na formação de professores de línguas. In: GIMENEZ, T.; MONTEIRO, M. C. G. (Org.). Formação de professores de línguas na América Latina e transformação social. Campinas: Pontes, 2010. v. 4. p. 57-67. COELHO, H. S. C. Experiências, emoções e transformações na educação continuada: um estudo de caso. 2011. 176 f. Tese (Doutorado em Linguística Aplicada) - Faculdade de Letras, Universidade Federal de Minas Gerais, Belo Horizonte. 2011. Disponível em: <http://www.bibliotecadigital.ufmg.br/dspace/handle/1843/DAJR8H5QQD>. Acesso em: 14 out. 2015. 
COSTA, G. S. Mobile Learning: explorando potencialidades com o uso do celular no ensinoaprendizagem de língua inglesa como lingua estrangeira com alunos da escola pública. 2013. Tese (Doutorado em Letras) - Universidade Federal de Pernambuco, Recife. 2013. Disponível em: <http://www.pgletras.com.br/2013/teses/TESE-Giselda-dosSantos-Costa.PDF>. Acesso em: 3 fev. 2016.

DUMAN, G.; ORHON, G; GEDIK, N. Research trends in mobile assisted language learning from 2000 to 2012. ReCALL, Cambridge, UK, v. 27, n. 2, p. 197-216, 2015. DOI: http://dx.doi.org/10.1017/S0958344014000287. Acesso em: 2 fev. 2016.

DUTRA, D. P.; MELLO, H. R. Pesquisas em linguagem: o que elas revelam sobre um projeto de educação continuada. In: TELLES, J. A. (Org.). Formação inicial e continuada de professores de línguas. Campinas: Pontes, 2009. p. 67-81.

GARDNER. R. C.; MACINTYRE, P. D. On the measurement of affective variables in second language learning. Language Learning, Cambridge, v. 43, p. 157-194, 1993.

HORWITZ, E. K. Language anxiety and achievement. Annual Review of Applied Linguistics, Cambridge, UK, v. 21, n. 1, p. 112-126, 2001. DOI: http://dx.doi. org/10.1017/S0267190501000071. Acesso em: 14 set. 2015.

HUANG, S. C. Raising learner-initiated attention to the formal aspects of their oral production through transcription and stimulated reflection. International Review of Applied Linguistics in Language Teaching, Berlin, v. 46, n. 4, p. 375-392, 2008. DOI: http://dx.doi.org/10.1515/IRAL.2008.016. Acesso em: 2 fev. 2016.

LYNCH, T. Learning from the transcripts of an oral communication task. ELT Journal, Oxford, v. 61, n. 4, p. 311-320, 2007.

MATURANA, H. Uma abordagem da educação atual na perspectiva da biologia do conhecimento. In: MATURANA, H. Emoções e linguagem na educação e na política. Belo Horizonte: UFMG, 1998. p. 11-35.

MATURANA, H.; VARELA, F. A árvore do conhecimento. São Paulo: Palas Athena, 2001.

MCNEIL, L. Ecological affordances and anxiety in an oral asynchronous computer mediated environment. Language Learning \& Technology, Honolulu, v. 18, n. 1, p. 142-158, 2014. Disponível em: <http://llt.msu.edu/issues/february2014/ mcneil.pdf $>$. Acesso em: 2 fev. 2016.

MICCOLI, L. Ensino e aprendizagem de inglês: experiências, desafios e possibilidades. Campinas: Pontes Editores, 2010.

NORTON, B. Identity and language learning: extending the conversation. London: Longman, 2013. 
PAIVA, V. L. M. O. Memórias de aprendizagem de professores de língua inglesa. Contexturas, São Paulo, v. 9, p. 63-78, 2006. Disponível em: <http://www. veramenezes.com/narprofessores.htm>. Acesso em: 4 fev. 2016.

PAIVA, V. L. M. O. As habilidades orais nas narrativas de aprendizagem de inglês. Trabalhos em Linguistica Aplicada, Campinas, v. 46, n. 2, p. 139-304, 2007. Disponível em: <http://www.scielo.br/pdf/tla/v46n2/a03v46n2.pdf>. Acesso em: 17 out. 2015.

PAIVA, V. L. M. O. Aquisição e complexidade em narrativas multimídia de aprendizagem. Revista Brasileira de Linguística Aplicada, Belo Horizonte, v. 8, p. 321-339, 2008. Disponível em: <http://www.scielo.br/pdf/rbla/v8n2/04.pdf>. Acesso em: 17 out. 2015.

PAIVA, V. L. M. O. Tecnologias digitais para o desenvolvimento de habilidades orais em inglês. 2014. Projeto de Pesquisa. Faculdade de Letras, Universidade Federal de Minas Gerais, Belo Horizonte. 2014.

PARKINSON, B.; FISCHER, A. H.; MANSTEAD, A. S. R. Emotion in social relations: cultural, group, and interpersonal processes. Philadelphia: Psychology Press, 2004.

PAVLENKO, A. The affective turn in SLA: From "affective factors" to "language desire" and "commodification of affect". In: GABRYS-BARKER, D.; BIELSKA, J. (Ed.). The affective dimension in second language acquisition. Bristol: Multilingual Matters, 2013. p. 13-28.

PEGRUM, M. Mobile learning: languages, literacies and cultures. London: Palgrave Macmillan, 2014.

POP, A.; TOMULETIU, E. A.; DAVID, D. EFL speaking communication with asynchronous, voice tools for adult students. Procedia: Social and Behavioral Sciences, New York, v. 15, n. 2, 1199-1203, 2011. Disponível em: < http://www.sciencedirect. com/science/article/pii/S1877042811004411>. Acesso em: 2 fev. 2016.

POZA, M. I. C. The effects of asynchronous computer voice conferencing on L2 learners' speaking anxiety. The International Association for Language Learning Technology Journal, [s.1.], v. 41, n. 1, p. 33-63, 2011. Disponível em: <http://old.iallt. org/iallt_journal/the_effects_of_asynchronous_computer_voice_conferencing_ on_12_learners_speaking_anxiety >. Acesso em: 4 fev. 2016.

REINDERS, H.; WATTANA, S. Can I say something? The effects of digital game play on willingness to communicate. Language Learning \& Technology, Honolulu, v. 18, n. 2, p. 101-123, 2014. Disponível em: <http://llt.msu.edu/issues/june2014/ reinderswattana.pdf $>$. Acesso em: 4 fev. 2016.

REZENDE, T. Autoestudo sobre as emoções de uma professora de inglês em uma escola pública. 2014. 141 f. Dissertação (Mestrado em Estudos Linguísticos) - Universidade 
Federal de Viçosa, Viçosa. 2014. Disponível em: < http://www.locus.ufv.br/ handle/123456789/4893>. Acesso em: 17 nov. 2014.

SANTAELLA, L. Aprendizagem ubíqua no contexto da educação aberta. Revista Tempos e Espaços em Educação, São Cristóvão, Sergipe, v. 14, p. 15-22, 2014. Disponível em: <http://www.seer.ufs.br/index.php/revtee/article/view/3446/3010>. Acesso em: 2 fev. 2016.

SCOVEL, T. The effect of affect on foreign language learning: A review of the anxiety research. Language Learning, Ann Arbor, v. 28, n. 1, p. 129-142, 1978.

SIBILIA, P. Redes ou paredes: a escola em tempos de dispersão. Rio de Janeiro: Contraponto, 2012.

SONG, J. W. An investigation into the effects of an oral English diary using a voice bulletin board on English spoken performance. Multimedia-Assisted Language Learning, Seoul, v. 12, n. 1, p. 125-150, 2009.

SULLER, D. The online disinhibition effect. Cyberpsychology \& Behavior, New York, v. 7, n. 3, p. 321-326, 2004.

SUN, Y. C. Voice blog: An exploratory study of language learning. Language Learning \& Technology, Honolulu, v. 13, n. 2, p. 88-103, 2009. Disponível em: <http://llt. msu.edu/vol13num2/sun.pdf>. Acesso em: 2 fev. 2016.

TELLES, J. Reflexão e identidade professional do professor de LE: que histórias contam os futuros professores? Revista Brasileira de Linguistica Aplicada, Belo Horizonte, v. 4, n. 2, p. 57-83, 2004. Disponível em: < http://www.scielo.br/pdf/ rbla/v4n2/04.pdf>. Acesso em: 17 out. 2015.

YANGUAS, I.; FLORES, A. Learners' willingness to communicate in face-to-face versus oral computer mediated communication. JaltCall Journal, Tokyo, v. 10, n. 2, p. 83-103, 2014. Disponível em: < http://journal.jaltcall.org/articles/10_2_ Yanguas.pdf $>$. Acesso em: 17 out. 2015.

Data de submissão: 25/04/2016. Data de aprovação: 03/10/2016. 